\title{
EL LIDERAZGO Y LA COOPERACIÓN ORGANIZACIONAL SON ARGUMENTOS CLAVES PARA APRENDER EN UN ESCENARIO DE PANDEMIA
}

\author{
Leadership and organizational cooperation are key \\ arguments to learn in a pandemic scenario
}

\section{Tomas Gabriel Bas ${ }^{1}$}

Los factores sociales, económicos y culturales que promueven la cooperación son claves en el mundo organizacional y la muestra de liderazgo cruciales para la solución de los diferentes problemas que atañen a las sociedades en su conjunto. Referenciar a las organizaciones farmacéuticas en tiempos de pandemia como la que se vive desde el año 2020 es una obviedad y donde la cooperación y el liderazgo entre estos actores del mundo de la salud se hacen cruciales. A partir de esta noción, surgen la pregunta ¿De qué manera se puede promover la valoración de la diversidad del conocimiento organizacional e industrial y qué elementos o estrategias del ámbito del liderazgo en innovación, podrían ayudar a salir fortalecidos de esta crisis pandémica?

Antes de abordar estrictamente la pregunta es importante saber que si no se conoce el problema, difícilmente se pueda abordar la solución, y ese es un punto clave para las organizaciones involucradas, ya que nos centramos muchas veces en la solución y no sabemos quién o qué genera el problema. Visto desde esta perspectiva y en un contexto de pandemia como el que afrontamos y que está lejos de terminar, pareciera ser muy apropiada, porque hasta ahora la mirada ha estado puesta especialmente en contar con una vacuna que resuelva el problema con el SARS-CoV2, pero no en su origen, a pesar de que hay muchos intentos, pero aún no hay una respuesta clara aceptada por toda la comunidad científica. La pandemia está asociada a una multiplicidad de factores que, de persistir, nos auguran nuevas pandemias cíclicas.

Entonces hay una serie de elementos que se deben considerar las sociedades y sus organizaciones, como es el aprender a trabajar desde la divergencia hacia la convergencia para definir y dar soluciones a los distintos problemas que van surgiendo, teniendo en cuenta que se hace frente a una de las mayores incertidumbres de la historia de la humanidad en materia de salud pública global. Esa perspectiva, que implica colaboración y liderazgo ha sido una de

\footnotetext{
${ }^{1}$ Profesor Asociado Gestión de Innovación Tecnológica, Escuela de Ciencias Empresariales, Universidad Católica del Norte (Coquimbo), Chile. tomas.bas@ucn.cl
} 
las mayores lecciones que este periodo nos está dejando. Entonces, ¿Cómo resolver un problema que nos atañe a todos de la mejor manera posible y en el menor tiempo? Este desafío sin precedentes ha dejado al descubierto la necesidad de dejar mezquindades de lado para cooperar a nivel internacional y enfrentar esta crisis de dimensiones globales.

En este contexto ¿Qué elementos de liderazgo han sido claves para fomentar la cooperación social y organizacional en este escenario de pandemia? Hay que ser justos en reconocer que la pandemia fue tan fulminante, que no dio tiempo a una reacción inmediata de parte de las autoridades gubernamentales, ni sanitarias de los países implicados inicialmente. Al mismo tiempo, dejó al desnudo las falencias propias de una globalización desmesurada y la falta de controles eficientes desde lo sanitario como aduanero ante una importante epidemia que se expandía a una velocidad nunca antes vista, que más tarde se transformaría en la mega pandemia que conocemos hoy. Cuando se declara el estado de emergencia de salud en Wuhan (China), los países se quedaron especulando y tomaron a la ligera lo que sucedía en esa ciudad china, comportándose al principio como meros espectadores, a pesar de que ya se hablaba de un virus potencialmente mortal y desconocido, que estaba provocando estragos en la población local. La preocupación se centraba en información mediática sin mayor relevancia científica, como si el hecho de alimentarse con murciélagos o de convivir asiduamente con ciertos animales en el mercado local, era lo que había permitido una mutación del virus y que quedaría circunscripta localmente. En este sentido, el liderazgo de los gobiernos y organizaciones internacionales más influyentes, se hizo esperar de manera casi dramática. No se tomaron los recaudos necesarios ni a nivel global, ni a nivel local, para confinar a los potenciales transmisores del virus, un poco por falta de preparación e incapacidad de las autoridades competentes y otro, por falta de liderazgo, desidia e irresponsabilidad ante tal magnitud del evento que estaba a punto de explotar. Se hizo caso omiso a las señales que se presentaban y se siguió casi indiferente ante la tragedia que se avecinaba. La pandemia golpeó sin importar el grado de desarrollo de los países, tanto pobres como ricos. Sin embargo y cuando la primera ola ya se expandía sobre el globo a una velocidad fulgurante y a pesar de lo expresado, comienzan a verse respuestas embrionarias de cooperación internacional, lideradas por la Organización Mundial de la Salud (OMS). En este sentido, se vieron numerosos atributos de liderazgo que fueron claves a nivel internacional para intentar contener un mal mayor que ya se escapaba de las manos. Los líderes de Europa, tomaron cartas en el asunto, aunque de manera tardía siguiendo los lineamientos incipientes dictados por la OMS, debido en parte al desconocimiento del accionar del virus y ello provocó cadenas de falencias. Hubo confusión de los implicados en cómo reaccionar, en la forma de comunicar y cuáles eran las mejores opciones para contrarrestar al enemigo microscópico. Aun así hubo un liderazgo incipiente y mal organizado de la OMS y del continente europeo que reaccionaron tomando medidas, algunas tardías, lo que se ve reflejado en la cantidad de contagios y muertes por SARS-CoV2 que mostraron.

Sin embargo, todo ha sido bivalente, es decir, por un lado la pandemia muestra que no estábamos preparados para hacer frente a una situación de tal envergadura, pero por otro, muestra que una vez desatada la misma, hubo intentos de establecer lazos de cooperación internacional liderada justamente por la OMS, implicando a los distintos países y estos siguiendo los lineamientos y las recomendaciones emanados por el mayor ente mundial. En esta órbita de cooperación, hay una excepción marcada por los Estados Unidos, quien pasó de ser un líder innato en cooperación, pero desde un proteccionismo local, lo que mostró la falta de solidaridad global ante esta crisis que vivimos. El virus SARS-CoV2 demostró ser nefasto para la salud humana, pero más peligroso es la falta de solidaridad y empatía que se pudo observar desde el interior de algunas naciones. A pesar de ello, algunos gobiernos han mostrado un cierto liderazgo, particularmente, los europeos, que se revelaron también cooperativos, ayudando desde lo económico y sanitario a crear rápidamente hospitales de 
campaña, lidiar con los fallecidos y equipar con insumos a los hospitales tradicionales y al personal sanitario, imponiendo las normas de sanidad a respetar, los diferentes tipos de confinamientos, al tiempo que se notaba una falla en un punto primordial en toda crisis, como fue el comunicacional, así como los yerros de parte de la OMS. También se trabajó desde el liderazgo de manera cooperativa a nivel mundial en el financiamiento masivo de carácter público y privado para la investigación básica y aplicada para empresas farmacéuticas, permitiendo acortar dramáticamente los tiempos de respuesta y de desarrollo normal de una vacuna. Un elemento muy importante fue el compromiso de las editoriales de revistas de investigación más importantes del mundo a liberar sus publicaciones científicas, para que fueran accesibles a todas las personalidades dedicadas a la investigación sobre este virus, con lo que se vio el liderazgo y cooperativismo más grande de la historia en temas de investigación, ganando un tiempo precioso en intentar entender y por lo mismo encontrar una respuesta al accionar del SARS-CoV2 que repercutió en avanzar rápidamente en vacunas y píldoras que controlaran de alguna manera este virus. En este ámbito, se pudo observar también que algunas empresas totalmente ajenas al mundo de la salud como es el caso de algunas automotrices cooperaron y mostraron un liderazgo jamás antes visto, ya que tuvieron que cambiar su cultura organizacional, para pasar de fabricar automóviles, como el caso de Mercedes-Benz-F1 quien comenzó a fabricar respiradores artificiales para cubrir la demanda creciente de este tipo de dispositivo, lo mismo sucedió con General Motors en Estados Unidos. Otras, como una empresa de cervezas sin alcohol de Chile, que transformó una parte de su infraestructura para utilizar el alcohol sobrante en fabricar alcohol gel.

No solo hay que tratar la pandemia, sino también lo que viene después de la misma, ya que el panorama es muy desolador a nivel socio-económico. Entonces un verdadero liderazgo, es aquel que promueve la inclusión de manera sistemática y comprometida y que se muestra como un verdadero agente de cambio con la necesaria capacidad de valorar la cooperación como solución a los problemas que se avecinan. Ese liderazgo se ve claramente cuando se escapa de lo que se conoce como zona de confort, es decir que colaborar entre individuos o sociedades similares, es mucho más cómodo que colaborar e interactuar con aquellos individuos o modelos que son diferentes. Por ello, el liderazgo, tiene que ser inclusivo y debe ser capaz de generar modos de cooperación para conectar de manera creativa, aprovechando la diversidad y comprendiendo la colaboración de las personas implicadas.

Esto nos lleva a querer saber ¿Qué factores sociales, económicos, culturales, promueven esta cooperación, en general, y especialmente en el ámbito de la innovación? La cooperación a nivel internacional no es fácil de conducir, ya que la desconfianza entre los actores es muy grande y las sociedades como las organizaciones lo reflejan a diario. Si se toma el caso de China y el manejo de la pandemia, aun hoy se desconfía de la manera en que el país asiático la ha manejado, tanto internamente, como globalmente. El presidente chino, Xi Jinping habla del éxito en la "guerra del pueblo" contra el coronavirus, pero no deja que ningún organismo de salud pública mundial investigue sobre el origen, la evolución y la dinámica del SARS-CoV2 y eso naturalmente genera desconfianza.

Sin embargo, en medio de la pandemia, ha habido una decisión política de invertir masivamente en investigar al SARS-CoV2, su manera de transmitirse, su contagio y por supuesto su efecto sobre la población humana a nivel mundial. Pero la implicación se dio de manera integral desde la institucionalidad de los países implicados de manera más o menos cooperativa, aunque con muchas deficiencias, por la sonada desconfianza entre las partes implicadas. Hubo desafíos desde la salud pública, desde las organizaciones farmacéuticas, desde lo económico financiero y desde lo comunicacional y si bien se ha ido mejorando, estamos lejos de resolver los diferentes problemas que ha ocasionado la pandemia y que no tienen que ver solamente con lo sanitario, sino con lo económico, social y empresarial y donde se 
nota una vez más, una falta de preparación y un desconocimiento de cómo reaccionar ante un enemigo tan microscópico como letal.

Entonces surge la pregunta ¿De qué manera se puede promover la real valoración de la creatividad organizacional? La uniformidad mata la creatividad, mientras que lo que la hace inconmensurable a una sociedad, es su diversidad y esto lo vemos muy bien en un paralelo con la endogamia en genética, donde los individuos por su similitud genética presentan problemas morfológicos y fisiológicos, por lo que se busca lo contrario, es decir favorecer la diversidad genética para potenciar las fortalezas. El término diversidad es muy potente, pero generalmente mal utilizado o comprendido y no se lo robustece a partir de la valoración que tiene lo que es diferente. Para innovar y crear valor debemos recurrir a la creatividad y dicha creatividad consiste justamente en valorar la diversidad de conocimientos, de competencias, de habilidades o capacidades diferentes y en esta conjugación, una vez más la cooperación juega un rol crucial en esta dinámica creativa y cruzada transversal. La riqueza de la diversidad es única y en esta diversidad, una vez más entran en juego los líderes natos que logran entender esta perspectiva y potenciar así dicha ventaja que se da a nivel competitivo y comparativo a quien la sabe explotar. Se requiere tener líderes con fuertes valores alineados a las necesidades de cada región creando valor a partir de ellas desde el ecosistema organizacional y empresarial.

Finalmente ¿Qué elementos o estrategias del ámbito del liderazgo en innovación, podrían ayudar a que América Latina saliera fortalecida de esta crisis sanitaria? La innovación es la clave del desarrollo, ya que sin ella no hay impulso creativo, ya sea individual, para una organización o una región determinada, pero para que ello se plasme, es fundamental alcanzar niveles de educación mucho más importantes que los que posee hoy América latina. La pobreza y las políticas públicas de apoyo, no están bien delineadas y la prueba es que esta parte del continente no puede salir del círculo vicioso en el que se encuentra inmerso desde siempre. Hay que apostar por la formación y el apoyo de líderes basados en una cultura de valores, diversidad, capacitación y generación de competencias que pongan en el eje del mundo al continente sudamericano. Las organizaciones de esta parte del planeta parten casi siempre en desventaja frente a aquellas de países altamente industrializados, ya que deben hacer frente netamente a la canalización adecuada de sus competencias e intereses $y$, los esfuerzos y estímulos necesarios para generar situaciones propicias a su crecimiento. A partir de esta perspectiva, se necesita alcanzar estándares que hagan a los países y sus instituciones más competitivas en relación a lo logrado por los países líderes y que los lleve, si las condiciones son adecuadas, a realizar cambios en la forma de utilizar los recursos, el medio ambiente, el territorio, los mercados ya existentes o incluso crear nuevos.

El hecho de vivir una situación extrema como la pandemia, debiera hacernos recapacitar sobre nuestra fragilidad como individuos, donde las diferencias se atenúan rápidamente y nos obliga a ser más empáticos para la toma de decisiones correctas que atañen a la sociedad toda. Las organizaciones de salud, tanto médicas como farmacéuticas, así como las editoriales de revistas especializadas han sabido reaccionar con un grado de liderazgo nunca antes visto, cooperar y sacar productos en tiempo record que ayuden a combatir los efectos mortales del virus SARS-CoV2. Este tipo de mandato, no es otra cosa que la disposición de los recursos aprovechables y la correspondiente gestión de los distintos líderes referenciados que buscan resolver en tiempo récord problemas graves que nos conciernen a todos globalmente. 